\title{
Strengthening in-service training and continuing education (IST/ CE) for frontline health workers for Bauchi and Cross River states
}

\author{
Ekechi Okereke \\ Population Council \\ Godwin Unumeri \\ Population Council \\ Ibrahim Suleiman \\ Population Council \\ Aisha Jibril \\ Population Council
}

Follow this and additional works at: https://knowledgecommons.popcouncil.org/departments_sbsr-rh

Part of the Community Health Commons, Demography, Population, and Ecology Commons, Health Services Research Commons, and the International Public Health Commons How does access to this work benefit you? Let us know!

\section{Recommended Citation}

Okereke, Ekechi, Godwin Unumeri, Ibrahim Suleiman, and Aisha Jibril. 2019. "Strengthening in-service training and continuing education (IST/CE) for frontline health workers for Bauchi and Cross River states," Project brief. Abuja: Population Council. 


\section{INTRODUCTION}

A routine system for the continuous capacity building of frontline health workers, during their active employment, is currently non-existent in Nigeria's health system.

Opportunities for in-service training and continuing education (IST/CE) are few and far between for most frontline health workers. The Population Council, in partnership with the World Health Organization (WHO), during the Enhancing the Ability of Frontline Health Workers to Improve Health in Nigeria project was responsible for supporting Bauchi and Cross River states' development, implementation, and monitoring of costed annual in-service training and continuing education programs for their frontline health workers.

\section{BACKGROUND}

In 1998 WHO's Regional Committee for Africa adopted a Regional Strategy for HRH development ${ }^{1}$, acknowledging HRH's importance as a health system building block and key determinant of service provision and system efficacy ${ }^{2}$. Many low- and middle income countries have inadequate numbers of required health workers and managers, in addition to serious capacity gaps within their existing health workforces. Training health workers and their managers provides capacity-building necessary for achieving health system goals.

\section{ASSESSING PROJECT STATES' TRAINING NEEDS}

The Nigeria Frontline Health Worker project's implementation plan stipulated that the Population Council should conduct an extensive analysis of IST/CE in Bauchi and Cross River, along with training needs assessments for frontline health workers, as the basis for strengthening IST/CE in both states. The Population Council's HRH project team developed study protocols and data collection tools for the assessments, which were approved by the Council's Institutional Review Board (IRB) and each state's IRB.

To build research capacities in both states, discussions were held with their Ministry of Health officials to employ monitoring and evaluation (M\&E) officers as data collectors in each state. This approach promotes local investment in the research, its findings, and recommendations.
This HRH project, Enhancing the Ability of Frontline Health Workers to Improve Health in Nigeria, is a health systems-strengthening project implemented in Nigeria by Population Council, Global Health Workforce Alliance (GHWA), and the World Health Organization (WHO).

Funded by Global Affairs Canada (GAC), the project began in 2014 in two states, Cross River and Bauchi.

The HRH project works through the federal Ministry of Health and regulatory bodies, specifically NMCN and the Community Health Practitioners' Registration Board of Nigeria (CHPRBN), in addition to the pre-service health training institutions in the project states.

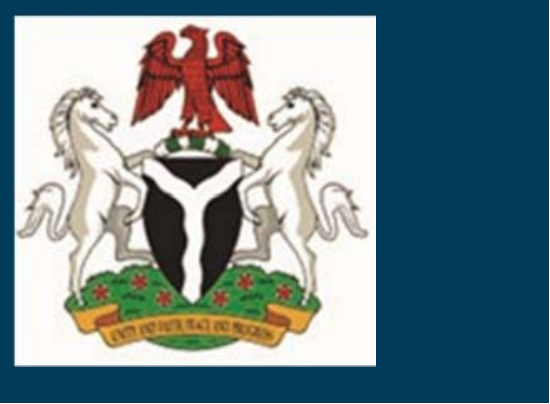


Data collectors' supervisors' training as well as subsequent fieldwork for the assessments occurred in the last quarter of 2016 in both states, with data analysis and dissemination of preliminary findings to key stakeholders in the first and second quarters of 2017.

The Council also discussed support for development of costed annual IST/CE work plans with officials and key stakeholders in both states, along with developing appropriate monitoring tools with the states' Health ministries and Primary Healthcare Development agencies.

\section{DEVELOPMENT AND IMPLEMENTATION OF COSTED IST/CE WORK PLANS}

In 2018, the Council facilitated workshops with Bauchi and Cross River stakeholders to develop costed annual IST/CE plans. Key objectives of these workshops were:

- To review and discuss key findings from the frontline health worker IST/CE situation analyses and needs assessments in both states

- To develop costed annual implementation plans for improving IST/CE, and

- To develop tools for monitoring and reporting the implementation of the IST/CE plans in Bauchi and Cross River.

Participants at these workshops included representatives from each state's Ministry of Health, Primary Healthcare Development Agency, Planning Commission, Office of Head of Service, Budget Office, Civil Service Commission, Ministry of Establishment and Training, as well as representatives from health training institutions.

The workshops resulted in costed annual work plans for implementing IST/CE in both states for 2019, in addition to monitoring and reporting tools for their implementation.

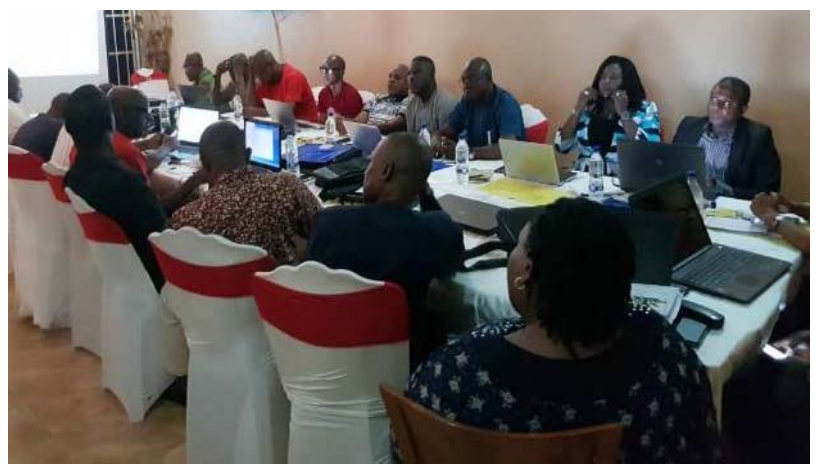

Workshop with Cross River stakeholders to develop the annual costed IST/CE work plan

\section{CONTACT US}

Ekechi Okereke HRH Project Director Population Council Nigeria eokereke@popcouncil.org
Godwin Unumeri HRH Program Administrator Cross River Population Council Nigeria gunumeri@popcouncil.org

Workshop participants agreed that further deliberation with a wider range of stakeholders, including the leadership of both states' health sectors, during policy dialogues, would build support for implementing their costed annual work plans as well as adopting the monitoring and reporting tools. These policy dialogues were facilitated by the Council's HRH team, during which the costed work plans were re-examined and endorsed.

A key recommendation from the policy dialogues was that stakeholders should ensure that the annual costed work plans for IST/CE are included in the 2019 Health budgets for both Bauchi and Cross River, to ensure sustainability.

\section{CONCLUSION}

Technical working groups were inaugurated to guide the implementation of the annual costed work plans for IST/CE in both Bauchi and Cross River. Bauchi's initial technical working group meeting was chaired by the Honourable Commissioner for Health Dr. Zuwaira Hassan Ibrahim, on 26 January 2019.

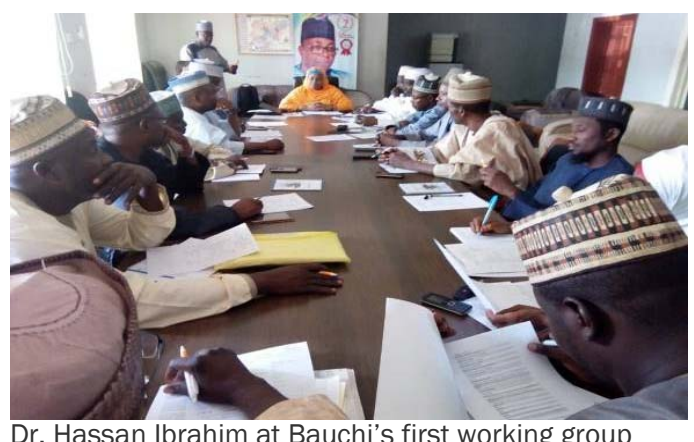

The success of the implementation of the IST/CE work plans now depends on the political will of health sector leadership in each project state, along with effective implementation of the $\mathrm{HRH}$ project's sustainability plan, led primarily by WHO, the lead partner of this HRH project in Nigeria.

\section{CITATIONS}

1. Nyoni J et al. 2006. Policies and Plans for Human Resources for Health: Guidelines for Countries in the WHO African Region. WHO Regional Office for Africa. Brazzaville.

2. WHO. 2002. Human Resources for Health: Developing Policy Options for Change. Draft Discussion Paper. Geneva.

Ibrahim Suleiman HRH Program Administrator Bauchi

Population Council Nigeria isuleiman@popcouncil.org
Aisha Jibril Program Officer Population Council Nigeria ajibril@popcouncil.org 